\title{
Evaluation of losses in a hydraulic motor based on the SWSB - 63 motor tests
}

Agnieszka Maczyszyn, M. Sc.

Gdańsk University of Technology

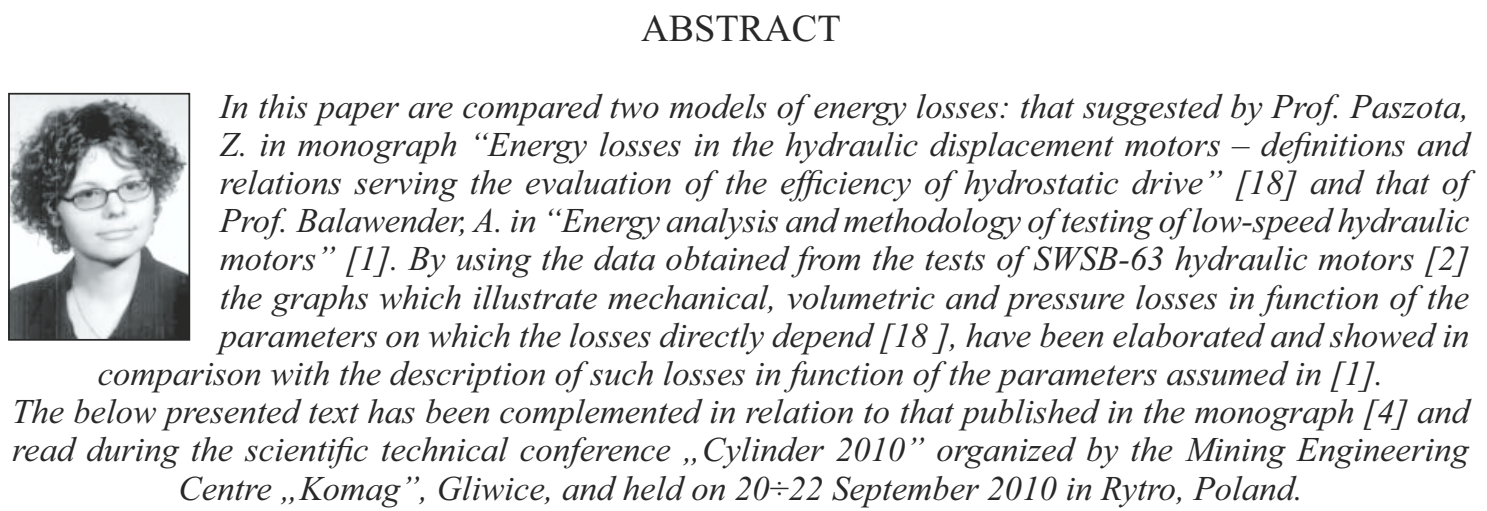

Keywords: hydrostatic drive and control; energy efficiency; power of energy losses

\section{INTRODUCTION}

Nowadays both client and producer are oriented towards quality, i.e. client to obtain high-quality products and producer to offer products of better and better quality by searching for ways to increase quality of products. Quality of a product can be increased for instance by searching for novel design solutions, manufacturing techniques or research methods. This paper is aimed at highlighting two approaches to losses generated in hydraulic displacement machines, precisely speaking hydraulic displacement motors.

The models of losses proposed by different authors and in different ways, show results of mechanical, volumetric and pressure losses obtained from tests of the same hydraulic motor.

One of the approaches is the ,anti-Sankey's” developed by Prof. Z. Paszota, who systematized the state of knowledge on losses and efficiencies appearing in hydraulic displacement motors [18]. The other approach is that of Prof. Balawender, A., which can be found in $[1,3]$.

The paper [18] made it possible to order and present, by this author, mechanical, volumetric and pressure losses in function of the parameters which directly influence their magnitude, and in consequence allowed to determine their real values. During determining the losses this author made use of the test results [2] dealing with SWSB-63 medium- pressure high- moment slow-speed motor whose design and description of tests have been contained also in [5].

\section{DESCRIPTION OF LOSSES OCCURRING IN HYDRAULIC MOTOR}

Mathematical description of losses occurring in hydraulic displacement machines has been considered since the instant of their invention. The elaborated formulae have been extended by adding new elements and terms associated with growing knowledge on the theme. The way has led a.o. through the achievements of such foreign researchers as: Wilson, Thoma, Prokofiev, Schlösser i Hilbrands, and Polish ones: Stryczek, Balawender and Paszota. Putting focus on the two last authors one is able to present and compare their points of view on losses occurring in hydraulic motors.

Prof. Balawender, A., [1, 3] splits the losses occurring in hydraulic motors into the following:

- moment losses represented by the following model:

$$
\begin{aligned}
& M_{\mathrm{s}}=\mathrm{C}_{\mathrm{Tk}} \mathrm{D}_{\mathrm{t}}^{3} \mathrm{p}_{0}+\mathrm{C}_{\mu} \mu_{0} \omega \mathrm{D}_{\mathrm{t}}^{3}+\mathrm{C}_{\mathrm{H} \rho} \rho \omega^{2} \mathrm{D}_{\mathrm{t}}^{3}+ \\
& +\mathrm{C}_{\mathrm{Tp}}\left[1+\mathrm{k}_{\mathrm{om}} \exp \left(-\omega \mu_{0} \Omega_{0}{ }^{-1}\right)\right] \mathrm{D}_{\mathrm{t}}{ }^{3} \mathrm{p}_{1}+\mathrm{C}_{\mathrm{Tr}} \mathrm{D}_{\mathrm{t}}^{3} \mathrm{p}_{1}
\end{aligned}
$$

where:

$\mathrm{C}_{\mathrm{Tk}}$ - proportionality coefficient associated with mechanical friction,

$\mathrm{D}_{\mathrm{t}}$ - characteristic dimension of hydraulic motor,

$\mathrm{p}_{0} \quad$ - atmospheric pressure,

$\mathrm{C}_{\mu}$ - proportionality coefficient associated with dynamic viscosity of working liquid, 
$\mu_{0} \quad-\quad$ dynamic viscosity coefficient of oil at the parameters $\left(\mathrm{p}_{\mathrm{o}}, \mathrm{T}_{1}\right)$,

$\omega$ - motor shaft angular velocity,

$\mathrm{C}_{\mathrm{Hp}}$ - proportionality coefficient associated with pressure losses in passages;

$\rho \quad$ - specific mass of working liquid at the pressure $p_{0}$,

$\mathrm{C}_{\mathrm{Tp}}$ - proportionality coefficient associated with mechanical friction,

$\mathrm{k}_{\mathrm{om}} \quad$ - the coeffcient expressed as follows: $\mathrm{k}_{\mathrm{om}}=\Delta \mathrm{M}_{\mathrm{oTm}} \cdot \mathrm{M}_{\mathrm{Tp}}{ }^{-1}$,

$\Omega_{0}$ - power exponent constant,

$\mathrm{C}_{\mathrm{Tr}}$ - proportionality coefficient associated with friction variability during starting-up,

$\mathrm{p}_{1} \quad$ - pressure at inlet to hydraulic motor.

- volumetric losses represented by the following models:

- for hydraulic motor without compensation of gaps:

$$
\begin{gathered}
\mathrm{Q}_{\mathrm{s}}=\mathrm{C}_{\mathrm{s}} \mathrm{V}_{\mathrm{t}} \Delta \mathrm{p} \omega(2 \pi)^{-1}+\mathrm{C}_{\mathrm{ol}} \mathrm{V}_{\mathrm{t}} \Delta \mathrm{p}\left(2 \pi \mu_{0}\right)^{-1}+ \\
+\mathrm{C}_{\mathrm{ot}}\left(2 \Delta \mathrm{p} \rho^{-1}\right)^{-0,5}\left[\left(0,5 \mathrm{~V}_{\mathrm{t}} \pi^{-1}\right)^{2}\right]^{1 / 3}+\mathrm{C}_{\mathrm{oz}} \mathrm{V}_{\mathrm{t}} \mathrm{p}_{2}\left(2 \pi \mu_{0}\right)^{-1}
\end{gathered}
$$

where:

$\mathrm{C}_{\mathrm{s}}$ - proportionality coefficient depending on pressure and angular velocity,

$\mathrm{V}_{\mathrm{t}} \quad$ - theoretical working volume of motor per unit shaft rotation,

$\Delta \mathrm{p} \quad$ - pressure drop in motor,

$\mathrm{C}_{\mathrm{ol}} \mathrm{C}_{\mathrm{ot}}-$ proportionality coefficient of laminar and turbular component of leakages,

$\mathrm{C}_{\mathrm{oz}} \quad$ - proportionality coefficient depending on external leakages,

$\mathrm{p}_{2} \quad$ - pressure at outlet from hydraulic motor.

It can observed that the volumetric losses are the sum of four components: the first term expresses the component depending on pressure and angular velocity $(\omega=2 \pi n)$, the second and third - the components due to internal leakages for laminar and turbulent flow, respectively, and the fourth is the component depending on external leakages.

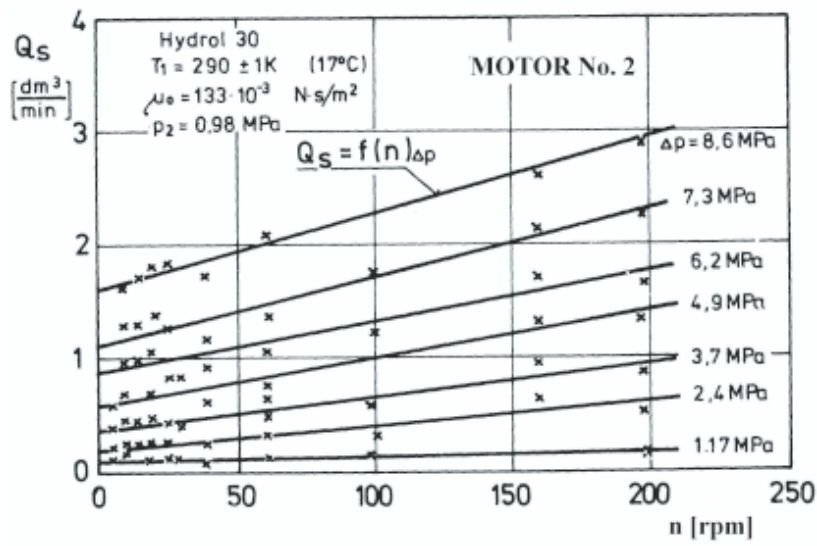

Fig. 1. Characteristics of total volumetric losses in the SWSB-63 motor, $Q_{S}=f(n)$, at $\Delta p=$ const, acc. [1]

- for hydraulic motor with compensation of gaps:

$$
\begin{aligned}
\mathrm{Q}_{\mathrm{s}}= & \mathrm{C}_{\mathrm{s}} \frac{\mathrm{V}_{\mathrm{t}}}{2 \pi} \Delta \mathrm{p} \omega+\frac{\mathrm{C}_{\mathrm{ol}}^{\prime}}{\mu_{0}} \frac{\mathrm{V}_{\mathrm{t}}}{2 \pi} \Delta \mathrm{p}\left(1+\mathrm{B}_{\mathrm{h}} \Delta \mathrm{p}\right)^{3}+ \\
& +\mathrm{C}_{\mathrm{ot}} \sqrt{\frac{2 \Delta \mathrm{p}}{\rho}} \sqrt[3]{\left(\frac{\mathrm{V}_{\mathrm{t}}}{2 \pi}\right)^{2}}+\frac{\mathrm{C}_{\mathrm{oz}}}{\mu_{0}} \frac{\mathrm{V}_{\mathrm{t}}}{2 \pi} \mathrm{p}_{2}
\end{aligned}
$$

where:

C'

$\mathrm{B}_{\mathrm{h}}$ - coefficient which characterizes operation of gaps compensation unit.

In the above given equation the element $\left(1+B_{h} \Delta p\right)^{3}$ accounting for gaps compensation unit in motor is added to the component associated with internal leakages for laminar flow.

In Fig. 1 and 2 are presented the diagrams elaborated in [1], which illustrate the above mentioned relationships based on the tests of SWSB-63 motor [2].

In the Prof. Paszota's publications $[5 \div 19]$ attention has been paid to the fact that losses occurring in hydraulic motors and pumps are presented either in function of the parameters which simultaneously depend on the losses or in function of the parameters which do not influence the losses directly. The relationships of losses in hydraulic motor, which have been published so far by Prof. Paszota, Z. [18, 19], are presented below:

- the moment $\mathrm{M}_{\mathrm{Mm}}=\mathrm{f}\left(\mathrm{M}_{\mathrm{M}}, \mathrm{n}_{\mathrm{M}}, v\right)$ of mechanical losses in the unit "shaft-working chambers" is a function of the moment $M_{M}$ exerted to motor shaft, demanded shaft rotational speed $\mathrm{n}_{\mathrm{M}}$, and working liquid viscosity $v$ [18]. In [19] is presented mathematical description of the moment of losses, $\mathrm{M}_{\mathrm{Mm}}$, in the unit ,shaft-working chambers”, as follows:

- for motor of the theoretical (constant) absorbing capacity $\mathrm{q}_{\mathrm{Mt}}$ per unit rotation of shaft:

$$
\begin{gathered}
\mathrm{M}_{\mathrm{Mm} \mid \mathrm{M}_{\mathrm{M}}, \mathrm{n}_{\mathrm{M}}, \mathrm{b}_{\mathrm{M}}=1, \mathrm{v}}=\left(\mathrm{k}_{7.1 .1}+\mathrm{k}_{7.1 .2} \frac{\mathrm{n}_{\mathrm{M}}}{\mathrm{n}_{\mathrm{Mt}}}\right) . \\
\cdot \mathrm{M}_{\mathrm{Mt}}\left(\frac{\mathrm{v}}{\mathrm{v}_{\mathrm{n}}}\right)^{\mathrm{a}_{\mathrm{vm}}}+\mathrm{k}_{7.2} \mathrm{M}_{\mathrm{M}}= \\
=\left(\mathrm{k}_{7.1 .1}+\mathrm{k}_{7.1 .2} \frac{\mathrm{n}_{\mathrm{M}}}{\mathrm{n}_{\mathrm{Mt}}}\right) \frac{\mathrm{q}_{\mathrm{Mt}} \mathrm{p}_{\mathrm{n}}}{2 \pi}\left(\frac{\mathrm{v}}{\mathrm{v}_{\mathrm{n}}}\right)^{\mathrm{a}_{\mathrm{vm}}}+\mathrm{k}_{7.2} \mathrm{M}_{\mathrm{M}}
\end{gathered}
$$

where:

$\mathrm{n}_{\mathrm{Mt}}$ - theoretical speed of motor shaft,

$\mathrm{M}_{\mathrm{Mt}}^{\mathrm{Mt}}$ - theoretical moment of motor,

$v / v_{n}$ - ratio of the viscosity $v$ and working liquid reference viscosity $v_{\mathrm{n}}=35 \mathrm{~mm}^{2} \mathrm{~s}^{-1}$,

$a_{v m}$ - exponent which describes impact of $v / v_{n}$ on magnitude of moment of mechanical losses in piston displacement motor of liquid -filled casing,

$p_{n} \quad$ - nominal pressure of system,

$\mathrm{k}_{\mathrm{i}}$ - coefficients of losses given by the following expressions:

$$
\begin{gathered}
\mathrm{k}_{7.1 .1}=\frac{\mathrm{M}_{\mathrm{Mm} \mid \mathrm{M}_{\mathrm{M}}=0, \mathrm{n}_{\mathrm{M}}=0, \mathrm{~b}_{\mathrm{M}}=1, \mathrm{v}_{\mathrm{n}}}}{\mathrm{M}_{\mathrm{Mt}}} \\
\mathrm{k}_{7.1 .2}=\frac{\mathrm{M}_{\mathrm{Mm} \mid \mathrm{M}_{\mathrm{M}}=0, \mathrm{n}_{\mathrm{M}}=\mathrm{n}_{\mathrm{Mt}}, \mathrm{b}_{\mathrm{M}}=1, \mathrm{v}_{\mathrm{n}}}-\mathrm{M}_{\mathrm{Mm} \mid \mathrm{M}_{\mathrm{M}}=0, \mathrm{n}_{\mathrm{M}}=0, \mathrm{~b}_{\mathrm{M}}=1, v_{\mathrm{n}}}}{\mathrm{M}_{\mathrm{Mt}}} \\
\mathrm{k}_{7.2}=\frac{\mathrm{M}_{\mathrm{Mm} \mid \mathrm{M}_{\mathrm{M}}=\mathrm{M}_{\mathrm{Mt}}, \mathrm{n}_{\mathrm{M}}=\mathrm{n}_{\mathrm{Mt}}, \mathrm{b}_{\mathrm{M}}=1, v_{\mathrm{n}}}-\mathrm{M}_{\mathrm{Mm} \mid \mathrm{M}_{\mathrm{M}}=0, \mathrm{n}_{\mathrm{M}}=\mathrm{n}_{\mathrm{Mt}}, \mathrm{b}_{\mathrm{M}}=1, v_{\mathrm{n}}}}{\mathrm{M}_{\mathrm{Mt}}}
\end{gathered}
$$

- for motor of the geometrical (variable) absorbing capacity $\mathrm{q}_{\mathrm{Mgv}}$ per unit rotation of shaft: 

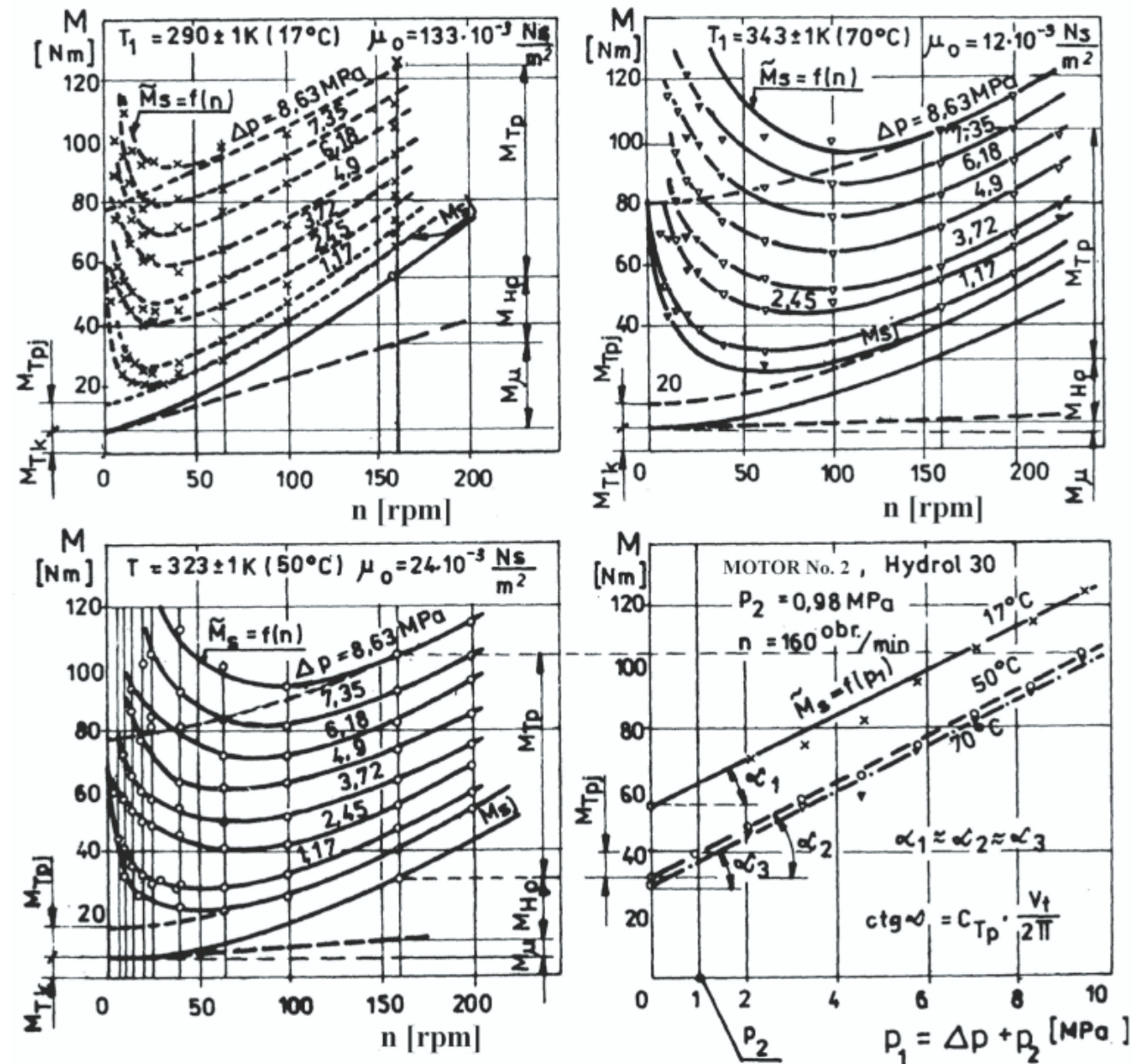

Fig. 2. Components of moment of losses in SWSB-63 motor for different oil temperature values, acc. [1]

$$
\begin{gathered}
\mathrm{M}_{\mathrm{Mm} \mid \mathrm{M}_{\mathrm{M}}, \mathrm{n}_{\mathrm{M}}, \mathrm{b}_{\mathrm{M}}, \mathrm{v}}=\left(\mathrm{k}_{7.1 .1}+\mathrm{k}_{7.1 .2} \frac{\mathrm{n}_{\mathrm{M}}}{\mathrm{n}_{\mathrm{Mt}}} \mathrm{b}_{\mathrm{M}}\right) \\
\cdot \mathrm{M}_{\mathrm{Mt}}\left(\frac{\mathrm{v}}{\mathrm{v}_{\mathrm{n}}}\right)^{\mathrm{a}_{\mathrm{vm}}}+\mathrm{k}_{7.2} \mathrm{M}_{\mathrm{M}}= \\
=\left(\mathrm{k}_{7.1 .1}+\mathrm{k}_{7.1 .2} \frac{\mathrm{n}_{\mathrm{M}}}{\mathrm{n}_{\mathrm{Mt}}} \mathrm{b}_{\mathrm{M}}\right) \frac{\mathrm{q}_{\mathrm{Mt}} \mathrm{p}_{\mathrm{n}}}{2 \pi}\left(\frac{\mathrm{v}}{\mathrm{v}_{\mathrm{n}}}\right)^{\mathrm{a}_{\mathrm{vm}}}+\mathrm{k}_{7.2} \mathrm{M}_{\mathrm{M}}
\end{gathered}
$$

where:

$\mathrm{b}_{\mathrm{M}}$ - coefficient of motor setting.

- the intensity $\mathrm{Q}_{\mathrm{Mv}}=\mathrm{f}\left(\Delta \mathrm{p}_{\mathrm{Mi}}, \mathrm{n}_{\mathrm{M}}, v\right)$ of volumetric losses in working chambers is a function of the pressure drop $\Delta \mathrm{p}_{\mathrm{Mi}}$ indicated in the chambers and, to some extent, of the motor shaft rotational speed $\mathrm{n}_{\mathrm{M}}$ as well as the working liquid viscosity $v,[18]$

- the working liquid pressure losses $\Delta \mathrm{p}_{\mathrm{Mp}}=\mathrm{f}\left(\mathrm{Q}_{\mathrm{M}}, v\right)$ within motor passages are a function of the motor absorbing capacity $\mathrm{Q}_{\mathrm{M}}$ as well as the working liquid viscosity $v,[18]$.

The test results of energy losses in the SWSB-63 motor, [2], presented in function of the parameters specified in [18], are illustrated in Fig. $3 \div 9$

- The characteristics $\mathrm{M}_{\mathrm{Mm}}=\mathrm{f}\left(\mathrm{M}_{\mathrm{M}}\right)$ at $\mathrm{n}_{\mathrm{M}}=$ const and $v=$ const (Fig. 5) were determined on the basis of the data given in [2], by calculating, in addition, the moment $\mathrm{M}_{\mathrm{Mm}}$ of mechanical losses in the unit ,shaft-working chambers” (defined in [5]) as the difference of the moment $\mathrm{M}_{\mathrm{Mi}}$ indicated in working chambers (determined from the relation $\mathrm{M}_{\mathrm{Mi}}=0.5 \mathrm{q}_{\mathrm{Mt}} \Delta \mathrm{p}_{\mathrm{Mi}} \pi^{-1}$ ) and the motor shaft moment $\mathrm{M}_{\mathrm{M}}$.

- By linear approximating the curves given in Fig. $3 a \div c$, were obtained the data to draw the relation $\mathrm{M}_{\mathrm{Mm}}=\mathrm{f}\left(\mathrm{n}_{\mathrm{M}}\right)$ at $\mathrm{M}_{\mathrm{M}}=$ const and $v=$ const, shown in Fig. $4 \mathrm{a} \div \mathrm{c}$.

- The characteristics $\mathrm{M}_{\mathrm{Mm}}=\mathrm{f}(\mathrm{v})$ at $\mathrm{M}_{\mathrm{M}}=$ const and $\mathrm{n}_{\mathrm{M}}=$ $=2.67 \mathrm{~s}^{-1}$ (Fig. 5), were obtained on the basis of Fig. $3 \mathrm{a} \div \mathrm{c}$.

- The characteristics $\mathrm{Q}_{\mathrm{Mv}}=\mathrm{f}\left(\Delta \mathrm{p}_{\mathrm{Mi}}\right)$ at $\mathrm{n}_{\mathrm{M}}=$ const and $v=$ const (Fig. $6 \mathrm{a} \div \mathrm{c}$ ), were obtained by calculating the intensity $\mathrm{Q}_{\mathrm{Mv}}$ of volumetric losses in motor working chambers as the difference of the motor absorbing capacity $Q_{M}$ and the product of the theoretical absorbing capacity per unit rotation, $\mathrm{q}_{\mathrm{Mt}}$, and the motor shaft rotational speed $\mathrm{n}_{\mathrm{M}}$. The pressure drop $\Delta \mathrm{p}_{\mathrm{Mi}}$ indicated in motor working chambers was calculated as the difference of the pressure drop $\Delta \mathrm{p}_{\mathrm{M}}$ in motor and the liquid pressure losses $\Delta \mathrm{p}_{\mathrm{Mp}}$ in passages of the motor (acc. [5]).

- The characteristics $\mathrm{Q}_{\mathrm{Mv}}=\mathrm{f}\left(\mathrm{n}_{\mathrm{M}}\right)$ at $\Delta \mathrm{p}_{\mathrm{Mi}}=$ const and $v=$ const (Fig. $7 \mathrm{a} \div \mathrm{c}$ ) were obtained by approximating the curves in Fig. $6 \mathrm{a} \div \mathrm{c}$ with the use of trend lines (and trying to get the possible greatest probability; they represent exponential functions).

- The characteristics $\Delta \mathrm{p}_{\mathrm{Mp}}=\mathrm{f}\left(\mathrm{Q}_{\mathrm{M}}\right)$ at $v=$ const (Fig. $8 \mathrm{a} \div \mathrm{c}$ ) were drawn on the basis of the data taken from [2].

- The characteristics $\Delta \mathrm{p}_{\mathrm{Mp}}=\mathrm{f}(\mathrm{v})$ at $\mathrm{Q}_{\mathrm{Mt}}=$ const (Fig. 9) were obtained on the basis of the characteristics $\Delta \mathrm{p}_{\mathrm{Mp}}=\mathrm{f}\left(\mathrm{Q}_{\mathrm{M}}\right)$ (Fig. $8 \mathrm{a} \div \mathrm{c}$ ) by accounting for impact of liquid viscosity at the intensity equal to the theoretical absorbing capacity $\mathrm{Q}_{\mathrm{Mt}}$. 
a)

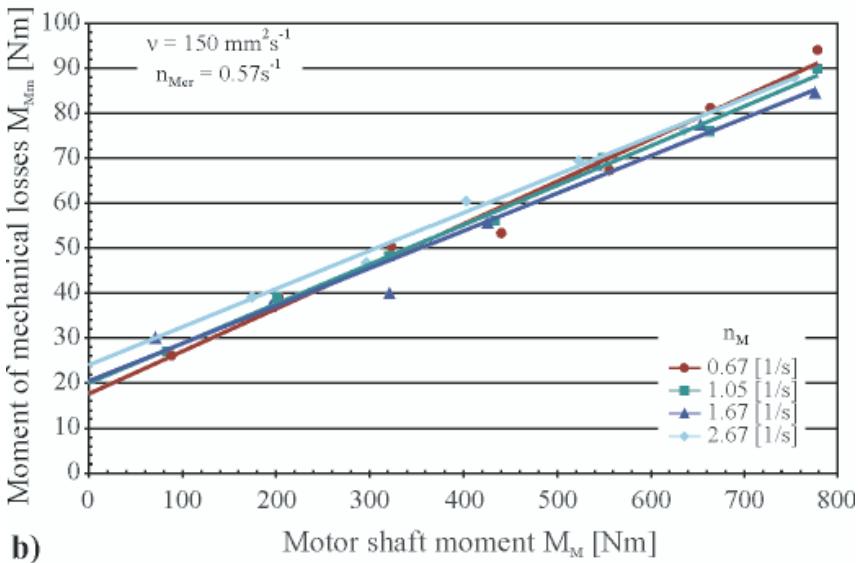

b)

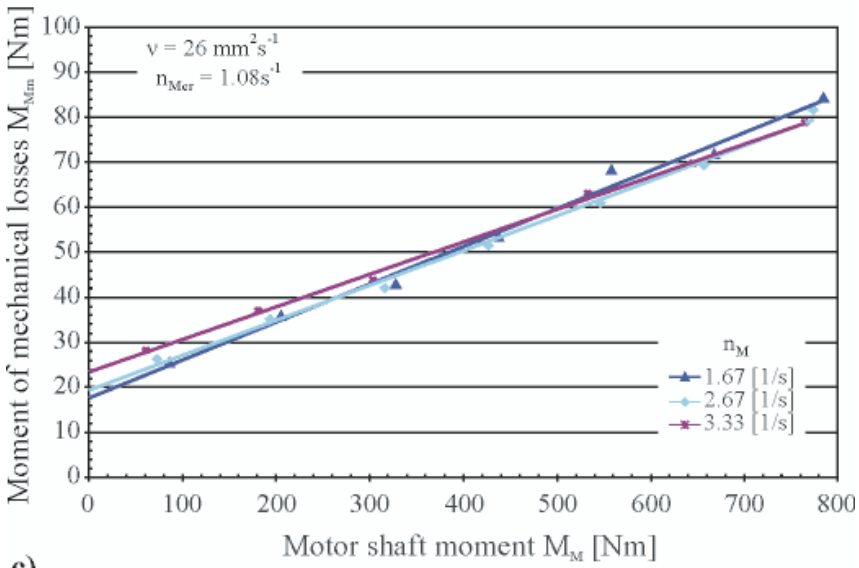

c)

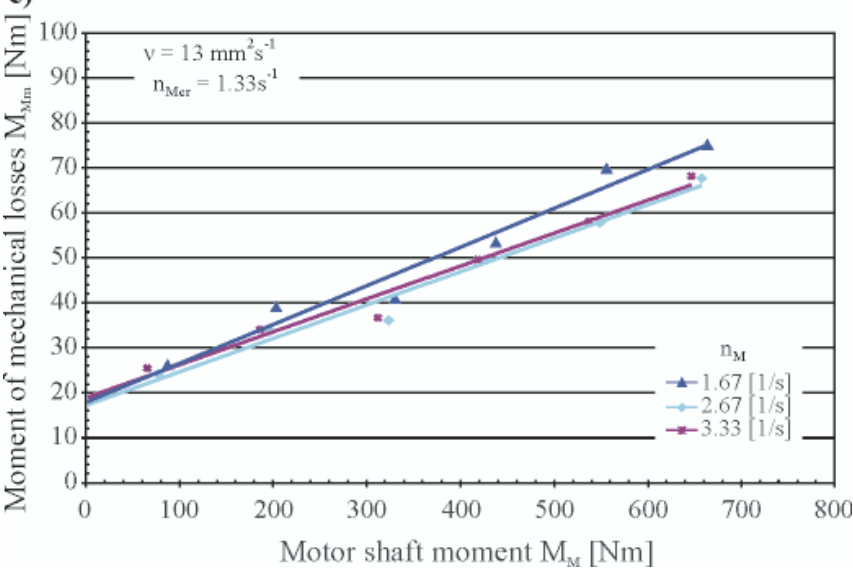

Fig. 3. The moment of mechanical losses in the unit ,, shaft-working chambers" $M$ of SWSB-63 motor in function of the shaft moment $M_{M}$ at steady values of the shaft rotational speed $n_{M}$; a) $v=150 \mathrm{~mm}^{2} \mathrm{~s}^{-1}$, b) $v=26 \mathrm{~mm}^{2} \mathrm{~s}^{-1}$; c) $v=13 \mathrm{~mm}^{2} \mathrm{~s}^{-1}$. As the critical shaft rotational speed $n_{M r^{\prime}}$ was assumed the speed below which the speed irregularity $\delta n_{M}$ is greater than $10 \%$

The critical rotational speed $n_{\text {Mcr }}$ was assumed on the level corresponding to the relatively high irregularity of motor rotational speed, $\delta \mathrm{n}_{\mathrm{M}} \approx 10 \%$. On the diagrams (Fig. $3 \div 7$ ), below the assumed value of the critical speed $\mathrm{n}_{\mathrm{Mcr}}$ such characteristics were not determined.

The theoretical absorbing capacity $\mathrm{Q}_{\mathrm{Mt}}$ was calculated as the product of the theoretical absorbing capacity per unit rotation, $\mathrm{q}_{\mathrm{Mt}}$, and the motor shaft theoretical rotational speed $\mathrm{n}_{\mathrm{Mt}}$.

\section{COMPARISON OF TWO ESTIMATIONS OF LOSSES WHICH OCCUR IN MOTOR}

1. The separation of mechanical losses (the moment, $\mathrm{M}_{\mathrm{Mm}}$, of mechanical losses in the unit , shaft-working chambers") a)

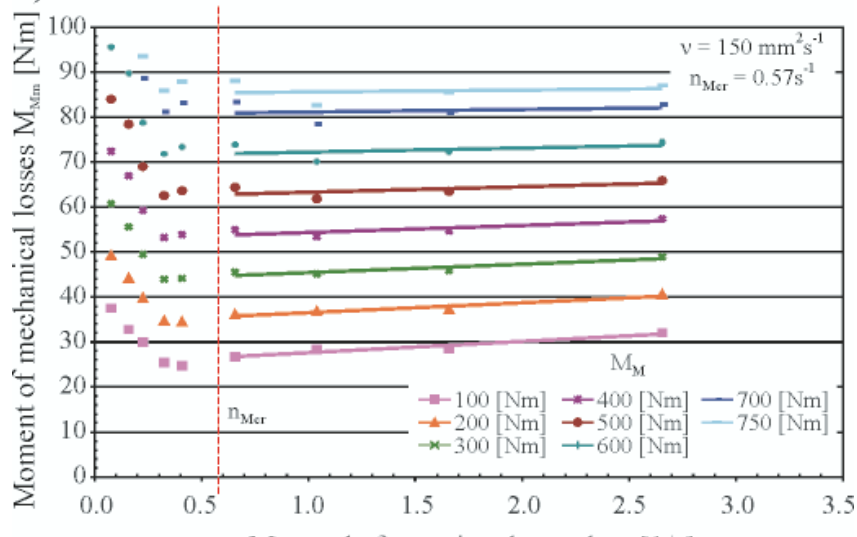

b)

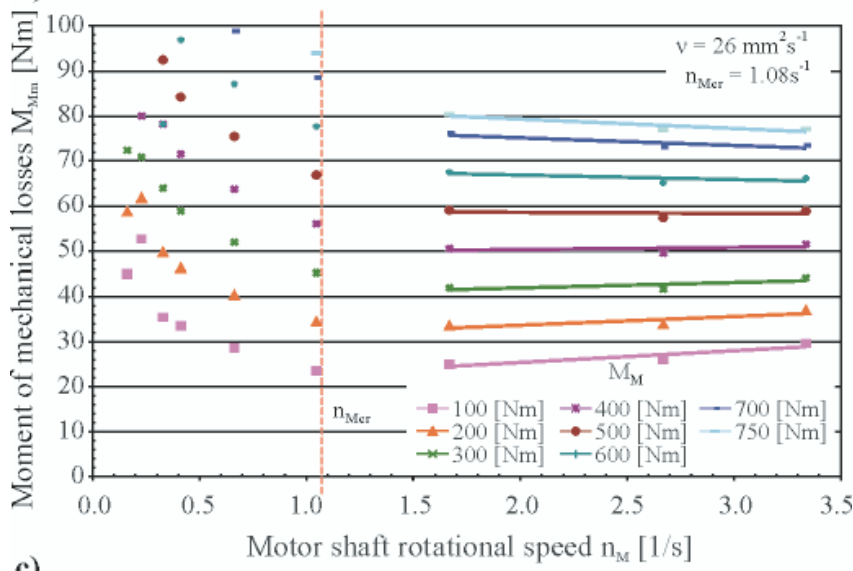

c)

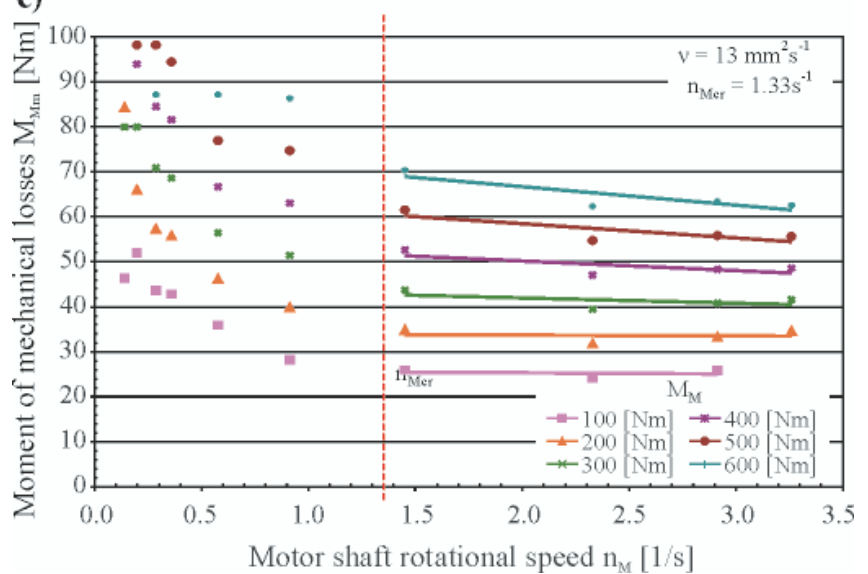

Fig. 4. The moment of mechanical losses in the unit ,, shaft-working

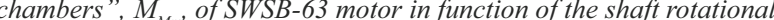
speed $n_{M}$ at steady values of the shaft moment $M_{\mu} ;$ a) $v=150 \mathrm{~mm}^{2} \mathrm{~s}^{-1}$, b) $v=26 \mathrm{~mm}^{2} \mathrm{~s}^{-1}$; c) $v=13 \mathrm{~mm}^{2} \mathrm{~s}^{-1}$. As the critical shaft rotational speed $n_{M c r^{2}}$ was assumed the speed below which the speed irregularity $\delta n_{M}$ is greater than $10 \%$

from the "hydraulic" ones (the working liquid pressure losses $\Delta \mathrm{p}_{\mathrm{p}}$ in working passages), proposed in [18], changes the image of the moment- of- losses characteristics (Fig. 2, $3,4,5)$ and their value. This can be observed in Fig. 2 where values of the moment of losses, $M_{s}$, at the steady rotational speed $n_{M}=2.67 \mathrm{~s}^{-1}(\mathrm{n}=160 \mathrm{rpm})$ and three constant values of the working liquid viscosity $v$, vary within the range of $30 \div$ $60 \mathrm{Nm}$, whereas values of the moment, $\mathrm{M}_{\mathrm{Mm}}$, of mechanical losses in the unit , shaft - working chambers” (Fig. 5) for the same viscosity values, in which the relationships given in [18] are taken into account, vary within the range of $17 \div 24 \mathrm{Nm}$

2. The moment of losses, $M_{s}$, (Fig. 2) presented in function of the rotational speed $\mathrm{n}$ and at steady values of the pressure 


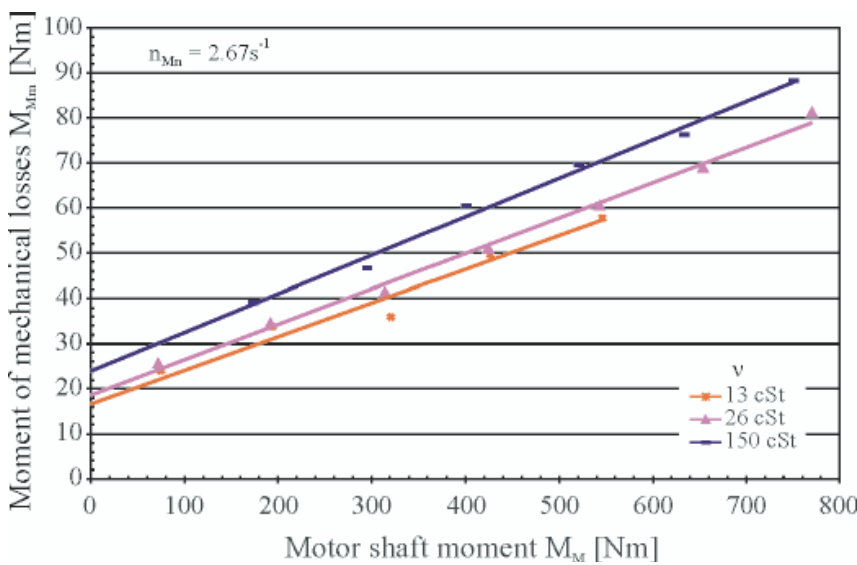

Fig. 5. The moment of mechanical losses in the unit, shaft-working chambers", $M_{M m}$, of SWSB-63 motor in function of the shaft moment $M_{M}$ at the theoretical shaft rotational speed $n_{\text {tit }}=2.67 \mathrm{~s}^{-1}$ and steady values of the working liquid viscosity $v$

drop $\Delta \mathrm{p}$ in motor, is influenced by mechanical losses in the unit ,shaft - working chambers", volumetric losses in working chambers, as well as pressure losses in motor passages. The moment, $\mathrm{M}_{\mathrm{Mm}}$, of mechanical losses in the unit ,shaft - working chambers" is presented in Fig. 3, 4 and 5, where it is demonstrated that, according to [18], the moment of mechanical losses, $\mathrm{M}_{\mathrm{Mm}}=\mathrm{f}\left(\mathrm{M}_{\mathrm{M}}, \mathrm{n}_{\mathrm{M}}, v\right)$, is a function of the demanded moment $\mathrm{M}_{\mathrm{M}}$ exerted to motor shaft, demanded shaft rotational speed $\mathrm{n}_{\mathrm{M}}$ as well as working liquid viscosity $v$.

3. In the diagrams showing the moment, $\mathrm{M}_{\mathrm{Mm}}$, of mechanical losses in the unit , shaft- working chambers" in function of the motor shaft moment $\mathrm{M}_{\mathrm{M}}$ and at steady values of the motor rotational speed $n_{M}$ (Fig. $\left.3 a \div c\right)$, can be observed correct relation between the moment $\mathrm{M}_{\mathrm{Mm} \mid \mathrm{M}_{\mathrm{M}}=0}$ of mechanical losses, determined at $\mathrm{M}_{\mathrm{M}}=0$, and the shaft rotational speed $n_{\mathrm{M}}$. The increasing shaft rotational speed $n_{M}$ is accompanied by the increasing moment $\mathrm{M}_{\mathrm{Mm} \mid \mathrm{M}_{\mathrm{M}}=0}$ associated with increasing inertia forces of structural elements as well as increasing friction forces between motor elements and working liquid. In the mathematical expressions which describe the moment of losses $\mathrm{M}_{\mathrm{Mm} \mid \mathrm{M}_{\mathrm{M}}=0}$ it is assumed that the increase is linear [19]. At greater loads it can be observed that rotational speed irregularity made the moment of losses increasing.

4. In order to keep the image readable, in Fig. $3 \mathrm{a} \div \mathrm{c}$ were depicted neither measurement points nor straight lines obtained from the measurements done at speed values below the critical speed $n_{\text {Mcr }}$ which turned out to be high though the speed was assumed that below which the speed irregularity $\delta \mathrm{n}_{\mathrm{M}}$ is greater than $10 \%$. The tested SWSB-63 motor was characterized by a great rotational speed irregularity, that resulted in difficulties in proper determining mechanical and volumetric losses.

The motor rotational speed irregularity is very high (of the order of $100 \%$ or even greater) at small values of the shaft speed $\mathrm{n}_{\mathrm{M}}$, large values of the moment $\mathrm{M}_{\mathrm{M}}$ and small values of the working liquid viscosity $v$. Then, mechanical losses grow and are difficult to be determined.

5. Neglecting the range of excessively great rotational speed irregularity (Fig. $4 \mathrm{a} \div \mathrm{c}$ ), one can observe that the increasing of the rotational speed $n_{M}$ leads to the increasing of the moment $\mathrm{M}_{\mathrm{Mm}}$ of mechanical losses in the unit ,shaft-working chambers"; this is specially visible at the large value of the viscosity $v=150 \mathrm{~mm}^{2} \mathrm{~s}^{-1}$, and less - at the smaller values of the viscosity $v=26 \mathrm{~mm}^{2} \mathrm{~s}^{-1}$ and

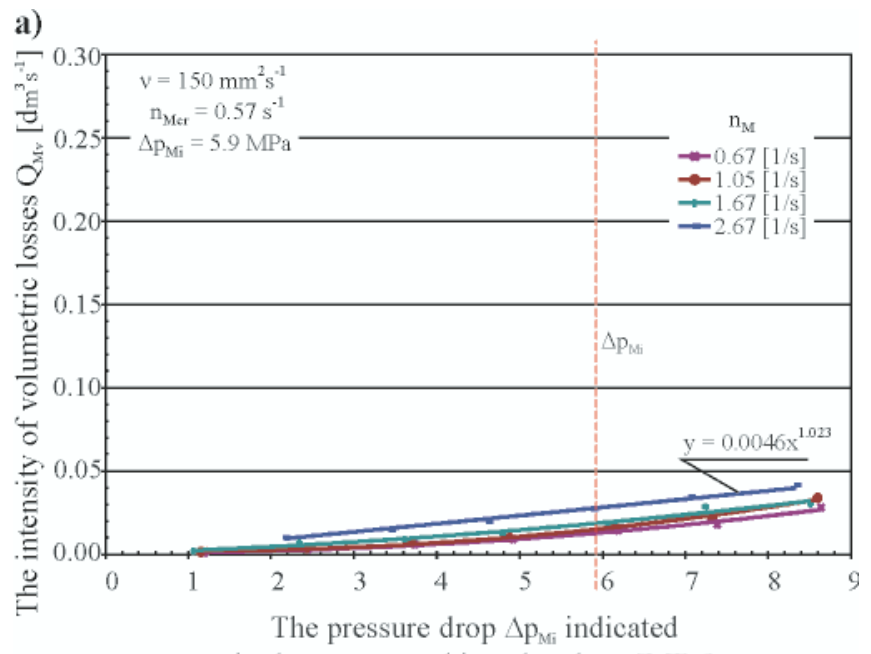

b) in the motor working chambers $[\mathrm{MPa}]$

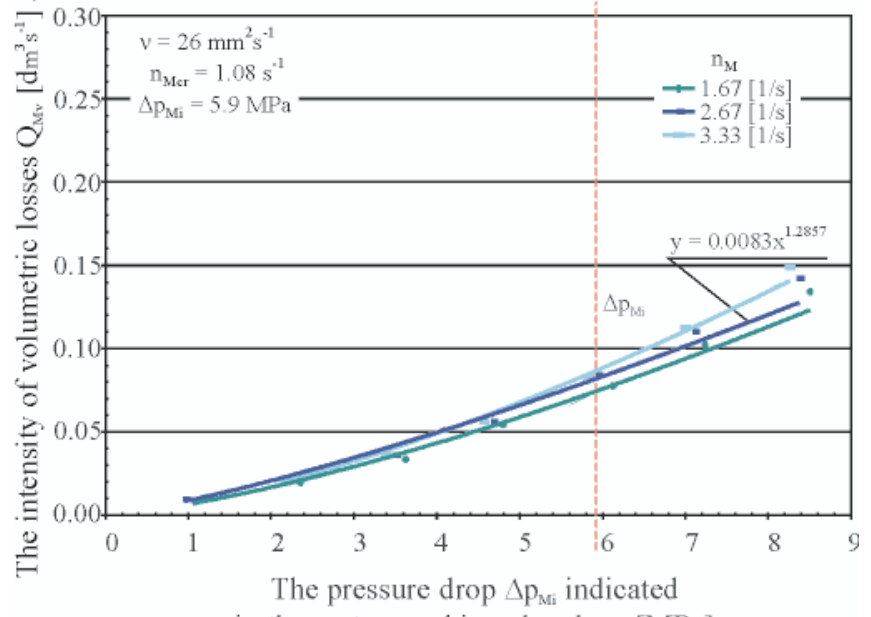

c)

in the motor working chambers [MPa]

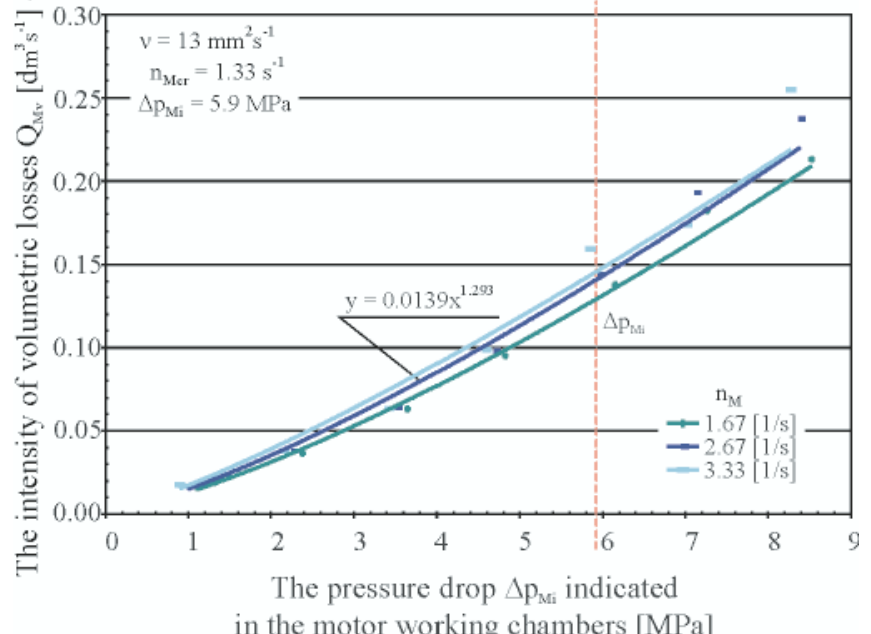

in the motor working chambers [MPa]

Fig. 6. The intensity, $Q_{M v}$ of volumetric losses in working chambers of SWSB-63 motor in function of the pressure drop $\Delta p_{M i}$ indicated in the working chambers at steady values of the shaft rotational speed $n_{M}$; a) $v=150 \mathrm{~mm}^{2} \mathrm{~s}^{-1}$; b) $v=26 \mathrm{~mm}^{2} \mathrm{~s}^{-1}$; ) $v=13 \mathrm{~mm}^{2} \mathrm{~s}^{-1}$. As the critical shaft rotational speed $n$ was assumed the speed below which

the speed irregularity $\delta n_{M}$ is greater than $10 \%$. The description of the function $y=f(x)$ given in the diagrams reflects only a character of the phenomenon but not its full mathematical description

$v=13 \mathrm{~mm}^{2} \mathrm{~s}^{-1}$. The increasing of the moment of mechanical losses along with the increasing of the shaft speed results from friction forces between elements of the unit, shaftworking chambers" and working liquid, and inertia forces of the unit's elements as well. 
a)

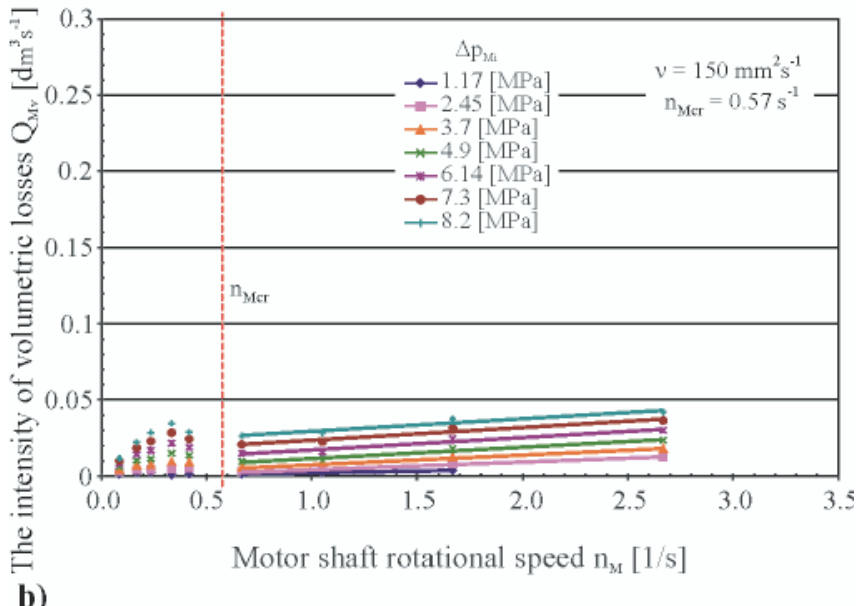

b)

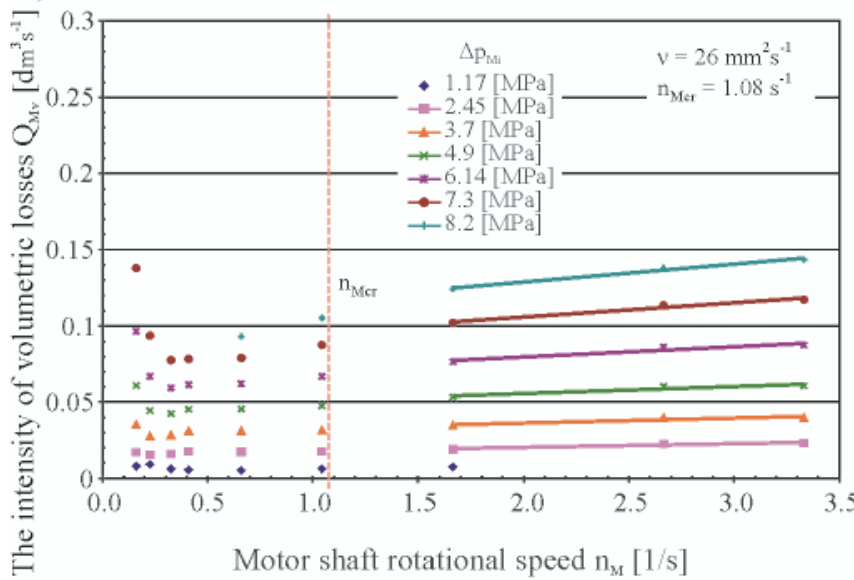

c)

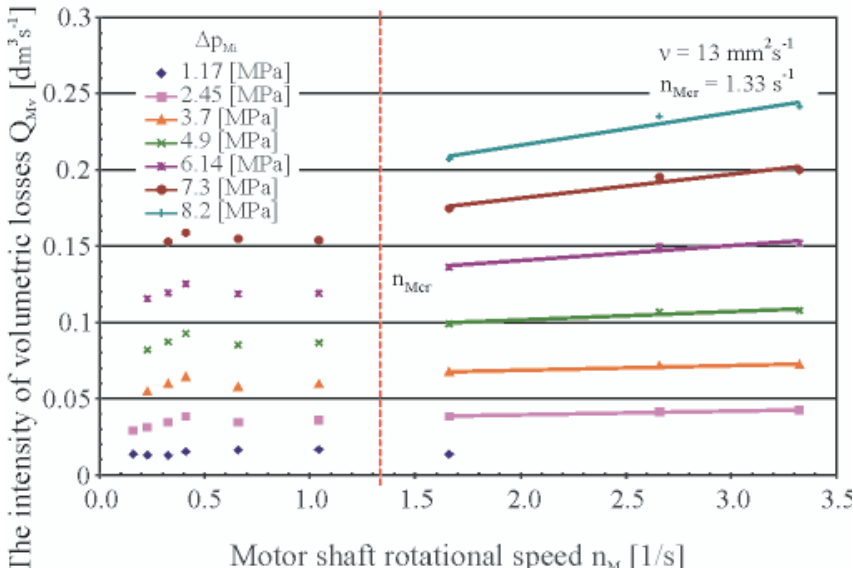

Fig. 7. The intensity, $Q_{M v}$ of volumetric losses in working chambers of SWSB-63 motor in function of the shaft rotational speeed $n_{M}$ at steady values of the pressure drop $\Delta p_{M i}$ indicated in the working chambers; a) $v=150 \mathrm{~mm}^{2} \mathrm{~s}^{-1}$; b) $v=26 \mathrm{~mm}^{2} \mathrm{~s}^{-1}$; ) $v=13 \mathrm{~mm}^{2} \mathrm{~s}^{-1}$. As the critical shaft rotational speed $n_{\text {we }}$ was assumed the speed below which the speed irregularity $\delta n_{M}$ is greater than $10 \%$

6. The images of the relationship of the moment, $\mathrm{M}_{\mathrm{Mm}}$, of mechanical losses in the unit "shaft-working chambers" (Fig. 4) and the moment $M_{s}$ of losses acc. Fig. 2 versus the rotational speed $\mathrm{n}_{\mathrm{M}}$, are entirely different. In Fig. 2 a very distinct increase of the losses moment along with the rotational speed increasing is observed, and in Fig. 4 the lines tend to go rather horizontally. Attention should be paid to the fact that because of irregular operation of the motor a part of measurement points in Fig. 4 was taken out and not accounted for, but in Fig. 2 lines were put through the points and that was accounted for in motor operation analysis. a)

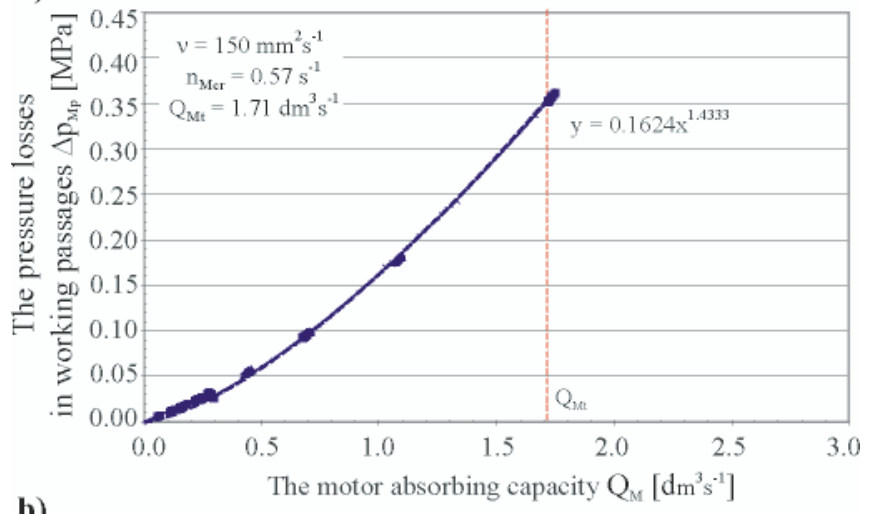

b)

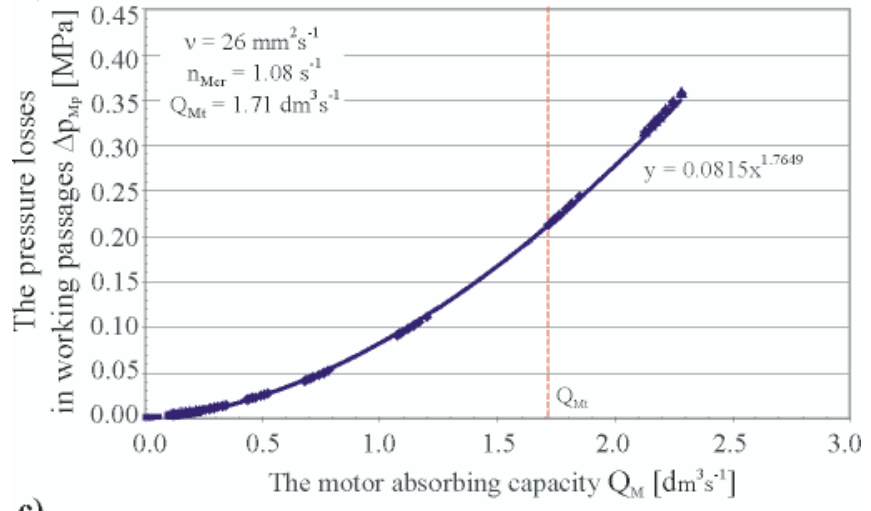

c)

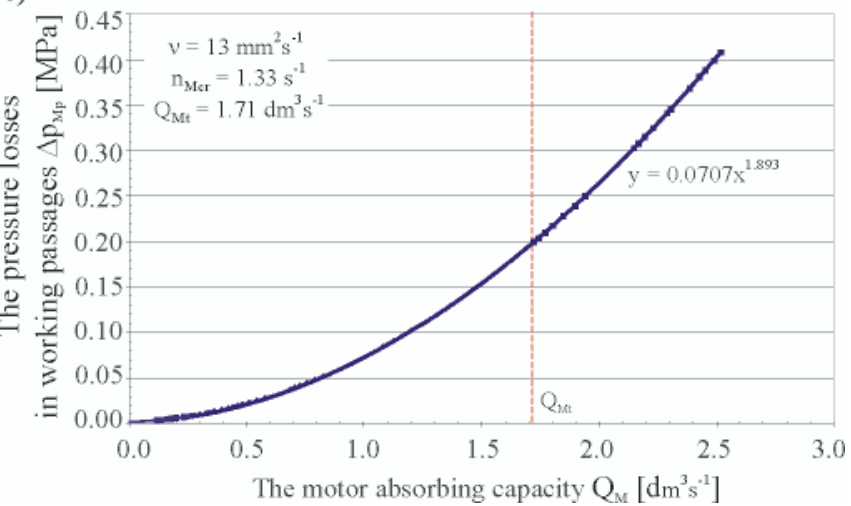

Fig. 8. The working liquid pressure losses, $\triangle p_{M p}$, in SWSB-63 motor passages in function of the motor absorbing capacity $Q_{M}$. a) $v=150 \mathrm{~mm}^{2} \mathrm{~s}^{-1}$; b) $v=26 \mathrm{~mm}^{2} \mathrm{~s}^{-1}$; c) $v=13 \mathrm{~mm}^{2} \mathrm{~s}^{-1}$.

The theoretical absorbing capacity $Q_{M t}=1.71 \mathrm{dm}^{3} \mathrm{~s}^{-1}$ was determined from the relation: $q_{n} \cdot n_{n}$, The description of the function $y=f(x)$ given in the diagrams reflects only a character of the phenomenon but not its full mathematical description

7. The impact of the working liquid viscosity $\mathrm{v}$ (mainly in motor casing) on the moment, $\mathrm{M}_{\mathrm{Mm}}$, of mechanical losses in the unit ,shaft- working chambers" in function of the shaft moment $\mathrm{M}_{\mathrm{M}}$ at the steady rotational speed $\mathrm{n}_{\mathrm{Mt}}=2.67 \mathrm{~s}^{-1}$ (Fig. 5) and determined for the shaft loading moment $\mathrm{M}_{\mathrm{M}}=0$, is described by the power exponent $\mathrm{a}_{\mathrm{vm}} \approx 0.15$, acc. [19].

8. The images of the relationship between the intensity, $\mathrm{Q}_{\mathrm{Mv}}$, of volumetric losses in motor chambers and the pressure drop, $\Delta \mathrm{p}_{\mathrm{Mi}}$, indicated in the chambers (Fig. 6), at steady values of the shaft rotational speed $\mathrm{n}_{\mathrm{M}}$ described by the exponential function $\mathrm{Q}_{\mathrm{Mv}} \sim \Delta \mathrm{p}_{\mathrm{Mi}}^{\mathrm{c}}$, make it possible to determine character of the losses associated with working liquid flow and simultaneous influence of changes in throttling gaps of the motor. The power exponent $c$ take the following values: a) $\left(v=150 \mathrm{~mm}^{2} \mathrm{~s}^{-1}\right) \mathrm{c}=1,02 ;$ b) $\left(v=26 \mathrm{~mm}^{2} \mathrm{~s}^{-1}\right) \mathrm{c}=1.29$, c) $\left(v=13 \mathrm{~mm}^{2} \mathrm{~s}^{-1}\right) \mathrm{c}=1.29$. The $\mathrm{c}$ - exponent values are greater than $\mathrm{c}=1$, hence it is possible to conclude that in 


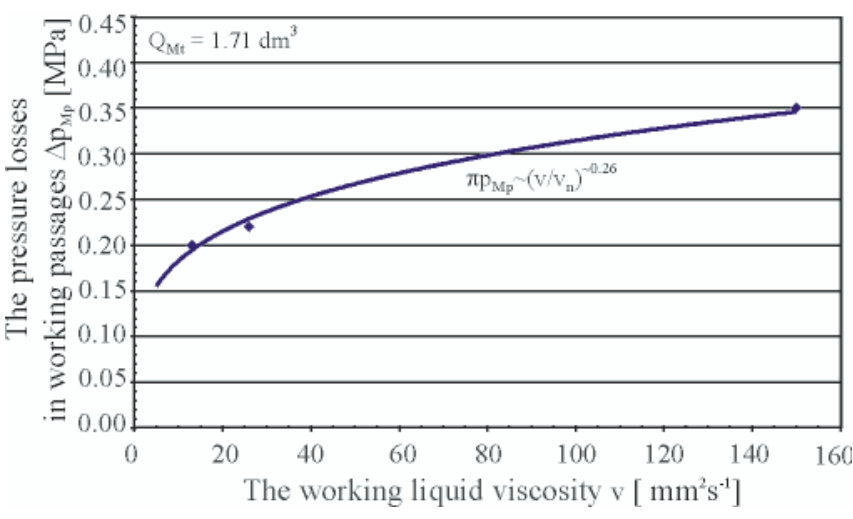

Fig. 9. The working liquid pressure losses $\triangle p_{M p}$ in SWSB-63 motor passages in function of the working liquid viscosity $v$ at the intensity equal to the theoretical absorbing capacity $Q_{M t}=1.71 \mathrm{dm}^{3} \mathrm{~s}^{-1}$

the tested motor the intensity, $\mathrm{Q}_{\mathrm{Mv}}$, of volumetric losses in working chambers is influenced by the cross-section area of the gaps in chambers, increasing along with $\Delta \mathrm{p}_{\mathrm{Mi}}$.

9. The impact of the working liquid viscosity $v$ on the intensity, $\mathrm{Q}_{\mathrm{Mv}}$, of volumetric losses in working chambers (Fig. 6), at $\Delta \mathrm{p}_{\mathrm{Mi}}=5.9 \mathrm{MPa}$ and the rotational speed $\mathrm{n}_{\mathrm{M}}=1.67 \mathrm{~s}^{-1}$, is determined by the power exponent $\mathrm{a}_{\mathrm{v} v}$ as follows: $\mathrm{Q}_{\mathrm{Mv}}$ $\sim\left(\mathrm{v} / \mathrm{v}_{\mathrm{n}}\right)^{\mathrm{avv}}[7]$, where $\mathrm{a}_{\mathrm{v} v} \approx-0.77$. And, at the theoretical rotational speed $\mathrm{n}_{\mathrm{Mt}}=2.67 \mathrm{~s}^{-1}$ the exponent value increases up to $\mathrm{a}_{\mathrm{vv}} \approx-0.62$. The $\mathrm{a}_{\mathrm{vv}}$ - exponent values make it possible to conclude that flow of volumetric losses through working chambers is of a turbulent character with an increasing degree of disturbance along with the increasing of the shaft rotational speed $n_{M}$.

10. The image of the relationship between the liquid pressure loss $\Delta \mathrm{p}_{\mathrm{Mp}}$ associated with its flow through working passages and the motor absorbing capacity $\mathrm{Q}_{\mathrm{M}}$ makes it possible to determine a character of working liquid flow through the passages by approximating the curves of Fig. $8 \mathrm{a} \div \mathrm{c}$ with the use of the exponential function $\Delta \mathrm{p}_{\mathrm{Mp}} \sim \mathrm{Q}_{\mathrm{M}}{ }^{\mathrm{d}}$ [6]. The determined power exponent $\mathrm{d}$ take the following values: a) $\left.\left(v=150 \mathrm{~mm}^{2} \mathrm{~s}^{-1}\right) \mathrm{d}=1.43 ; \mathbf{b}\right)\left(v=26 \mathrm{~mm}^{2} \mathrm{~s}^{-1}\right) \mathrm{d}=1.76$ c) $\left(v=13 \mathrm{~mm}^{2} \mathrm{~s}^{-1}\right) \mathrm{d}=1.89$. The $\mathrm{d}$ - exponent values make it possible to conclude that in the passages of the tested motor a not fully developed turbulent flow takes place along with the growing degree of disturbance accompanying the decreasing of the working liquid viscosity $v$.

11. The impact of the working liquid viscosity $v$ on the working liquid pressure drop $\Delta \mathrm{p}_{\mathrm{Mp}}$ in the passages (Fig. 8) was determined by using the power exponent $\mathrm{a}_{\mathrm{vp}}$ appearing in the relationship $\Delta \mathrm{p}_{\mathrm{Mp}} \sim\left(\mathrm{v} / \mathrm{v}_{\mathrm{n}}\right)^{\mathrm{a} v \mathrm{vp}}$ at the intensity equal to the theoretical motor absorbing capacity $\mathrm{Q}_{\mathrm{Mt}}=1.71 \mathrm{dm}^{3} \mathrm{~s}^{-1}$; then, its value was equal to $\mathrm{a}_{\mathrm{vp}} \approx 0.26$.

\section{CONCLUSIONS}

1. This paper is the first attempt to show the differences in assessing mechanical, volumetric and pressure losses occurring in hydraulic motor, resulting from that the assessments were made on the basis of different parameters. Two kinds of models of the losses were compared. The models proposed by Prof. Balawender, A. [1, 3] are very sophisticated, contain the parameters which themselves depend on the losses. The models of Prof. Paszota, Z., [18, 19], which are still under development, constitute the descriptions in which the losses are determined in function of the parameters which directly influence the losses, but are not dependent on them. The approach makes it possible to clearly present difference in assessing magnitude and proportion of the particular losses.
2. Correctness of such presentation of the moment, $\mathrm{M}_{\mathrm{Mm}}$, of motor mechanical losses occurring in the unit , shaft - working chambers" consists not only in elimination of „hydraulic" losses from it, but also in presentation of the moment of mechanical losses in function of the parameters which directly influence its magnitude, i.e. in function of the demanded motor shaft loading moment $\mathrm{M}_{\mathrm{M}}$, demanded rotational speed $\mathrm{n}_{\mathrm{M}}$, as well as in function of the working liquid viscosity $v$.

3. The presented mechanical losses $M_{M m}=f\left(M_{M}, n_{M}, v\right)$ in the unit , shaft-working chambers", the volumetric losses $\mathrm{Q}_{\mathrm{Mv}}$ $=\mathrm{f}\left(\Delta \mathrm{p}_{\mathrm{Mi}}, \mathrm{n}_{\mathrm{M}}, v\right)$ in working chambers and pressure losses $\Delta \mathrm{p}_{\mathrm{Mp}}=\mathrm{f}\left(\mathrm{Q}_{\mathrm{M}}, v\right)$ in motor passages have different character and are functions of different parameters, though it could at first glance seem that they are connected to each other by one common parameter, i.e the working liquid viscosity $v$. However its impact on particular losses is different. This was demonstrated with the use of the power exponent $a_{v}$ offerred by the method, proposed by Prof. Paszota $[5 \div 19]$, consisting in assessing particular kinds of losses by means of the loss coeffcients $\mathrm{k}_{\mathrm{i}}$ which make it possible - due to their universal description - to assess the losses not only in particular elements but also in the whole system.

\section{BIBLIOGRAPHY}

1. Balawender A.: Energy analysis and set of testing methods of slow-speed hydraulic motors (in Polish). Wydawnictwo Politechnika Gdańska (Gdańsk University of Technology Publishing House), Gdańsk 1988

2. Balawender A., Osiecki A., Paszota Z., Klimkiewicz W., Ciepielowski J.: Tests of the SWSB-63 large- moment mediumpressure hydraulic motor (in Polish). Scientific research project, Gdańsk University of Technology, Gdańsk 1972

3. Balawender A.: Physical and mathematical models of losses in hydraulic motors. In: Developments in Mechanical Engineering, Chapter 19, ed. Barylski, A., Ciesliński, J. T. Wydawnictwo Politechnika Gdańska (Gdańsk University of Technology Publishing House), Gdańsk 2005

4. Maczyszyn A.: Assessment of losses in hydraulic motor on the example of SWSB-63 motor tests (in Polish). A chapter of the monograph on „Research, designing, manufacturing and operating of hydraulic systems" (in Polish), ed. Klich A., Kozieł A., Palczak E. The library „Cylinder”. Centrum Mechanizacji Górnictwa „Komag” (Mining Industry Mechanization Centre), Gliwice 2010

5. Paszota Z.: Aspects energetiques des transmissions hydrostatiques. Wydawnictwo Politechnika Gdańska (Gdańsk University of Technology Publishing House), Gdańsk 2002

6. Paszota Z.: Model of pressure losses in displacement pump used in hydrostatic drive (in Polish). Materials of the $8^{\text {th }}$ Scientific Conference „, Ship Technology and Ocean Engineering” on „Development prospects of transport systems”. Międzyzdroje, 7-9 June 2006. Szczecin Technical University Publishing House, Szczecin 2006

7. Paszota Z:: Model of volumetric losses in displacement pump of variable capacity used in hydrostatic drive (in Polish). In: Napędy i Sterowanie 2006 (Drives and Control). The Scientific Technical Seminar "TECHNICON'06" accompanying the Fairs for Producers, Sub-contractors and Sellers of Drive Units and Control Systems, Gdańsk, 25 October 2006.

8. Paszota Z.: The power of energy losses in elements of hydrostatic drive system - definitions, relations, variability ranges, energy efficiences, Part I. Hydraulic motor (in Polish). Napędy i Sterowanie, No. 11(103), November 2007

9. Paszota Z.: Graphical presentation of the power of energy losses and power developed in elements of hydrostatic drive and control system, Part I-Rotational hydraulic motor speed series throttling control and volumetric control systems (in Polish). A chapter of the monograph on „Research, designing, 
manufacturing and operating of hydraulic systems" (in Polish), ed. Klich A., Kozieł A., Palczak E., The library „Cylinder”. Centrum Mechanizacji Górnictwa „Komag” (Mining Industry Mechanization Centre), Gliwice 2008

10.Paszota Z.: Graphical presentation of the power of energy losses and power developed in the elements of hydrostatic drive and control system, Part II - Rotational hydraulic motor speed parallel throttling control and volumetric control systems (in Polish). A chapter of the monograph on „Research, designing, manufacturing and operating of hydraulic systems" (in Polish), ed. Klich A., Kozieł A., Palczak E., The library „Cylinder”. Centrum Mechanizacji Górnictwa „Komag” (Mining Industry Mechanization Centre), Gliwice 2008

11.Paszota Z.: Direction of power flux increase in hydrostatic drive and control system. Graphical presentation of the power of energy losses and the power developed in elements of the system, Part I. - Rotational hydraulic motor speed series throttling control and volumetric control systems (in Polish). Napędy i Sterowanie, No. 10 (114), October 2008

12.Paszota Z.: Direction of power flux increase in hydrostatic drive and control system. Graphical presentation of the power of energy losses and the power developed in elements of the system, Part II. - Rotational hydraulic motor speed parallel throttling control and volumetric control systems (in Polish). Napędy i Sterowanie, No. 11 (115), November 2008

13.Paszota Z.: Graphical presentation of the power of energy losses and power developed in the elements of hydrostatic drive and control system. Part I - Rotational hydraulic motor speed series throttling control systems. Polish Maritime Research 3 (57), Vol. 15,2008

14.Paszota Z.: Graphical presentation of the power of energy losses and power developed in the elements of hydrostatic drive and control system. Part II - Rotational hydraulic motor speed parallel throttling control and volumetric control systems. Polish Maritime Research 4 (58),Vol. 15, 2008
15.Paszota Z.: The operating field of hydrostatic drive system (in Polish). A chapter of the monograph on ,Research, designing, manufacturing and operating of hydraulic systems" (in Polish), ed. Klich A., Kozieł A., Palczak E., The library „Cylinder”. Centrum Mechanizacji Górnictwa „Komag” (Mining Industry Mechanization Centre), Gliwice 2009

16.Paszota Z.: Parameters of efficiency investigations of hydraulic pumps and motors. Operating field of hydrostatic drive (in Polish). Napędy i Sterowanie, No. 11 (127), November 2009

17.Paszota Z.: The operating field of a hydrostatic drive system parameters of the energy efficiency investigations of pumps and hydraulic motor. Polish Maritime Research 4 (62), Vol. 16, 2009

18.Paszota Z.: Energy losses in hydraulic displacement motor definitions and relations for assessing efficiency of hydrostatic motor and drive (in Polish). A chapter of the monograph on „, Research, designing, manufacturing and operating of hydraulic systems" (in Polish), ed. Klich A., Kozieł A., Palczak E., The library „Cylinder”. Centrum Mechanizacji Górnictwa „Komag” (Mining Industry Mechanization Centre), Gliwice 2010

19.Paszota Z.: Theoretical and mathematical models of mechanical losses in rotational hydraulic motor used in hydrostatic drive (in Polish). A chapter of the monograph on ,Research, designing, manufacturing and operating of hydraulic systems" (in Polish), ed. Klich A., Kozieł A., Palczak E., The library „Cylinder”. Centrum Mechanizacji Górnictwa „Komag” (Mining Industry Mechanization Centre), Gliwice 2010.

\section{CONTACT WITH THE AUTHOR}

Agnieszka Maczyszyn, M. Sc.

Faculty of Ocean Engineering and Ship Technology,

Gdańsk University of Technology Narutowicza 11/12

80-233 Gdańsk, POLAND

e-mail: agnieszka.maczyszyn@pg.gda.pl 